\title{
LA CALIDAD DE GOBIERNO
}

\section{RESUMEN}

Dr. Patricio Moncayo, PHD. ${ }^{1}$

El artículo trata de la brecha entre los momentos electoral y gubernamental. Este desfase es analizado a la luz de los procesos de democratización ocurridos en las primeras décadas del siglo XXI.

Los autores consultados enfocan, desde distintos ángulos, la calidad de la democracia, en función de sus resultados.

Palabras Claves: buen gobierno, representación, prácticas políticas, gobernabilidad, situación, micropolítica, capacidad tecnopolítica

\section{ABSTRACT}

The article approaches the gap between two moments: elections and goverment. This i analyze in the democratic process ocurred at the beggining of this century.

The authors consulted discuss democratic quality, through different sights, pointing its outcomes.

Keyworks: good goverment, representation, policy practices, governance, situation, micropolitics, technopolitic capacity.

\footnotetext{
1 pmoncayo58@gmail.com

INVESTIGADOR INDEPENDIENTE
} 


\section{Introducción}

Se aprecia en el mundo un proceso de desvalorización de los resultados de la democracia. Hay un bajo porcentaje (el $28 \%$ promedio regional) que aprueba a los gobiernos por su desempeño (Informe para IDEA Internacional). La brecha entre el momento electoral y el siguiente, el momento del ejercicio gubernamental, ha dado lugar a frustraciones derivadas del incumplimiento de las promesas electorales. Esto ha traído cuestionamientos teóricos a la democracia electoral, y en la práctica a la aparición de nuevos autoritarismos.

El análisis que sigue quiere dar cuenta de esos cuestionamientos y evaluar el recorrido de los procesos de democratización en América latina en los últimos cuarenta años. Además pretende buscar en la práctica política las posibles causas de esta tendencia declinante y las posibles vías para revertir tal proceso.

Este análisis se fundamenta en los aportes del sociólogo francés Pierre Rosanvallon, en el Informe de un acreditado grupo de expertos en ciencias políticas sobre la situación de la democracia en la región (Informe para IDEA Internacional 2014) y en los estudios de Carlos Matus, experto en planificación y gobierno. En ellos se aprecia una crítica a la democracia electoral y una propuesta encaminada a combatir el mal gobierno.

El primero traza una línea conceptual sobre la teoría de la democracia. No se puede salir del atolladero solo desde la práctica de la gestión. El segundo hace un balance del recorrido de la democracia en América Latina, a partir de la calidad de la democracia, o sea, de los resultados de la gestión en la democracia, a las tres décadas y media de vida democrática. Se trata, dicen los autores, de un análisis equilibrado que se aleja tanto de una visión pesimista "como de una mirada simplista y autocomplaciente" $(2014,14)$. En él se registran los avances logrados, pero también los déficits y retos que enfrentan las democracias en la región.

El tercero provee de herramientas y técnicas para potenciar la gestión. Pienso que los tres enfoques abren el camino para producir una segunda revolución democrática que no se quede en la democracia de autorización, sino que avance a la democracia de ejercicio. (Rosanvallon, La democracia del siglo XXI, 2017).

Si bien se constata una expansión de la democracia (Elecciones presidenciales y giro político en América Latina, 2007) a juzgar por los procesos electorales recientes, la distancia entre las promesas electorales y la acción gubernamental ha mermado la credibilidad en la democracia. Hay, pues, un conflicto entre el fortalecimiento de la democracia electoral y la gestión de gobierno.
En primer lugar, se advierte que la política y los políticos se han visto atrapados por un estilo de hacer política que privilegia el inmediatismo. Los ciudadanos desconfían de las promesas de los políticos. No se sienten representados por ellos. El incumplimiento de las promesas electorales, ya se ha vuelto parte del paisaje, o sea, se ha naturalizado, como si se tratara de algo normal. Ello ha dado pie para el surgimiento de alternativas no encuadradas en los canales institucionales del Estado de Derecho.

El debate teórico entre democracia representativa y democracia participativa, ha tenido como trasfondo una polarización ideológica y política en torno a las relaciones entre estado y mercado. Pero la alternancia entre estos dos modelos- el neoliberal y el cifrado en la acción protagónica del estado- revela que la suerte de la democracia más que por el modelo que se adopte, está marcada por la manera cómo actúan los gobernantes en la práctica de su ejercicio como tales. La democracia no es un medio que se pone al servicio de un determinado modelo económico, sino que tiene su propia lógica y principios que le son esenciales. Son estos proyectos los que deben concordar con esos principios, entre los cuales figuran la libertad y la igualdad. La prevalencia de uno u otro depende de muchos factores. No solo de la voluntad de los gobernantes sino de las condiciones y circunstancias en medio de las cuales se ejercitan y practican los derechos políticos y sociales.

Una característica que se destaca en los procesos electorales de fines del siglo XX y las dos décadas del siglo XXI, es una cada vez mayor presencia ciudadana que tiende a desbordar a los partidos políticos. Ello, afirma Cheresky (Los desafíos democráticos en América Latina en Elecciones presidenciales y giro político en América Latina, 2007, 19-46) ha abonado el camino para el encumbramiento de liderazgos personales, así como los intentos de una auto representación de los ciudadanos a través de las redes sociales. En este escenario, sostiene este autor, la diferenciación política pesa menos que las realizaciones de gobierno. De ahí que ya se hable de la irrelevancia de las ideologías, como soporte de la actividad política. En su lugar gana fuerza el pragmatismo, y una conducción política errática.

Ante esa nueva situación, los conceptos clásicos de la teoría de la democracia se han visto confrontados por la realidad que se ha tornado mucho más compleja, lo cual exige la elaboración de nuevos conceptos. Los autores citados han acusado recibo de tal desfase, y aportan desde la teoría una nueva manera de abordar los déficits de la democracia.

Ésta es la primera parte del análisis que sigue. 


\section{El mal gobierno}

Pierre Rosanvallon en su último libro El Buen Gobierno (La democracia del siglo XXI, artículo publicado en la revista Nueva Sociedad, N-269 mayo-junio de 2017, 148 -162) cuestiona la teoría clásica de la elección, según la cual ésta es la piedra angular de la democracia. Sin desconocer el valor de las elecciones como fuente legítima del poder, considera que con ellas no se garantizan las funciones básicas de representación, legitimación, control sobre los representantes electos, expansión de la ciudadanía, incentivación de la deliberación pública. Muchos esfuerzos se hicieron para mejorar la calidad del proceso electoral, pero ello no dio los resultados esperados.

La representación sobre todo asociada a la función parlamentaria fue perdiendo fuerza, por la centralidad alcanzada por la función ejecutiva que devino en el verdadero poder del estado. La división de funciones dejó de ser la columna vertebral del estado de derecho. Más que el imperio de la ley, las decisiones que el Ejecutivo se ve obligado a tomar se convirtieron en el eje de la acción gubernamental. Los ciudadanos presionan más sobre el ejecutivo en demanda de soluciones que al Congreso. En éste se juega la representación pero no el espacio en el que se definen las relaciones entre gobernantes y gobernados. Para Rosanvallon estas relaciones han desplazado en importancia a las relaciones de representación.

La cabeza del Ejecutivo, sin embargo, no se da abasto. Su gobernabilidad, en términos de facultades y competencias, es mayor por el poder que tiene a su disposición, pero ello no deja de tener desventajas. Una de ellas es el ejercicio vertical del poder que ha desembocado en la presidencialización de las democracias. En estas condiciones las tentaciones autoritarias crecen, mientras los pesos y contrapesos, propios del Estado de Derecho, no funcionan o funcionan parcialmente, dejando al jefe del Ejecutivo sin el debido control por parte de los ciudadanos.

Ante esa ausencia de exigencias al cumplimiento de los mandatos, los ciudadanos consienten la personalización del poder, pues ello facilita la identificación de responsabilidad por las decisiones que un gobierno adopta, que se diluye en la legislatura. Semejante consentimiento tiene riesgos, entre los cuales figura el autoritarismo y el populismo. En este "contrato electoral" los ciudadanos devienen en sujetos pasivos o reactivos. Cunde la indiferencia ante el tipo de gobierno, y lo que cuenta es la capacidad para arreglar o mejorar sus problemas cotidianos. Así se extiende la disposición a sacrificar derechos y libertades a cambio de ventajas económicas. El clientelismo, el proteccionismo estatal, vulnera la noción de igualdad ante la ley.
Las elecciones parten de un supuesto que se ha vuelto cada vez más alejado de la realidad: la homogenización. El sufragio universal, por su propia naturaleza, no hace distingos. Sin embargo, los electores no son una masa. Mucho menos ahora, cuando asistimos al surgimiento y expansión del individualismo que desdibuja la vinculación de los individuos con la clase, la etnia o el género. La existencia individual tiene su propia dinámica que rebasa la identidad colectiva.

Esta puede ser una de las razones para la crisis de los partidos políticos. A su interior bullen intereses del más diverso tipo. La ideología ya no es garantía de cohesión. Ello también socava la representación.

Las elecciones dividen a los electores en mayorías y minorías. Pero tal división se sustenta en el número. La voluntad de todos no necesariamente representa a un conglomerado heterogéneo. El concepto de pueblo hace abstracción de las diferencias cualitativas de los electores. En esa perspectiva, según Rosanvallon, las minorías cuentan más que las mayorías. Es difícil articular a esas minorías alrededor de un programa de gobierno que marca una direccionalidad que quizá choca con los objetivos, intereses y valores de quienes en teoría lo suscriben. Mucho más con las expectativas y aspiraciones de los oponentes que adhieren a un programa diferente.

La política en esas condiciones se parece más a un juego de azar que a un cálculo racional. Lo situacional vuelve a imponerse en un mundo dominado por la incertidumbre. No existen certezas. Un gobierno tiene una limitada gobernabilidad que trata de ser contrarrestada por el fortalecimiento de la función del estado más próxima a las presiones y demandas de los ciudadanos.

El programa, dice Rosanvallon, era el vínculo entre el momento de la elección y el de la acción gubernamental. Roto ese vínculo, el gobierno navega a la deriva, y se ve atrapado por la urgencia. Pueden más las circunstancias que la voluntad de los gobernantes. La programación de la acción cede su espacio a la improvisación.

Esto se ve agravado por la temporalidad que rodea al acto electoral. La alternancia propia del juego democrático no permite que la acción gubernamental se proyecte más allá del período presidencial. El gobernante que entra en funciones, aunque hereda los resultados de quién le precedió, no se siente comprometido con las acciones y proyectos en ejecución y traza una línea de acción que no garantiza la continuidad necesaria para concluirlos. Esa situación se repite una y otra vez, lo que resta efectividad a la acción de gobierno. La tentación de garantizar la continuidad a través de la reelección es muy alta. Más todavía si quien ejerce el mando puede utilizar el poder que detenta para perennizarse en él. Estas incongruencias conducen las 
"fiestas electorales", como ficción de la democracia, a frustraciones que los ciudadanos suelen atribuir a la democracia, y no al mal gobierno. Ello se convierte en el caldo de cultivo de los partidos populistas que capitalizan las frustraciones ciudadanas y exacerban el resentimiento social contra las élites, a las que se les echa la culpa de la incapacidad gubernamental para atender con prontitud y eficacia a sus demandas.

\section{La democracia poselectoral}

A partir de la crítica a la democracia electoral, Rosanvallon propone rescatar sus principios adecuándolos a las nuevas realidades respecto de las que existieron cuando se produjo la primera revolución democrática que se tradujo en la conquista del sufragio universal.

La segunda revolución democrática, para Rosanvallon, consiste en crear mecanismos institucionales que permitan pasar de la democracia de autorización a la democracia de ejercicio. El sufragio universal concede al funcionario electo -en este caso al presidente- autorización para gobernar. Pero para evitar que esa autorización devenga en un cheque en blanco, hay que crear un código de conducta al que el presidente electo deba sujetarse en el ejercicio de su gobierno.

En cuanto a los ciudadanos, éstos no solo deben ser cuantificados, en función de su edad, la circunscripción territorial, la identidad étnica, de clase. Los electores son mucho más que meros sufragantes. Es necesario conocer más de ellos: sus condiciones de vida, sus necesidades, sus demandas. A los ciudadanos se los invisibiliza; éstos no son solamente un número, una cifra, un dato estadístico.

Una democracia responsable debe contar con una narrativa a través de la cual los ciudadanos sean tomados en cuenta. A ello pueden y deben contribuir la literatura, las ciencias sociales, la filosofía. Los gobernantes deben saber a quiénes gobiernan. Si no conocen a los gobernados mal pueden responder a sus requerimientos.

La invisibilidad, dice Rosanvallon, trae consigo el resentimiento social y el estallido de la cólera colectiva.

La gobernabilidad no es un tema exclusivamente estatal sino social. Si la igualdad ante la ley no es algo puramente formal, si la gente siente que es reconocida, que sus derechos son respetados, se crean condiciones para una mayor cohesión social. Si la gente no se conoce entre sí es inevitable que surja la desconfianza.

Es necesario rescatar el concepto de pueblo; éste no es solo una población que aumenta o disminuye, sino una amalgama de singularidades que poseen una existencia histórica.
Rosanvallon contrasta el mundo de los principios con el de la realidad empírica. Debe, según él, evitarse la "consumación de la expresión electoral mayoritaria tradicional" $(2017,155)$ y permitir que esa expresión no se diluya tras el acto eleccionario. Para ello se necesitan, agrega, autoridades independientes. La creación de instituciones basadas en este principio "ha modificado progresivamente la naturaleza y el alcance de los poderes Legislativo y Ejecutivo, tal como habían sido concebidos por la teoría liberal y democrática clásica" (2017, 156). Ello, por cierto, no puede darse automáticamente; requiere de procesos culturales que lo sostengan. Esto rebasa la esfera política, en la que los partidos políticos detentan el monopolio de la representación.

Hay una confusión entre la democracia como régimen y la democracia como una forma de gobierno. La implantación de un modelo presidencial - gobernante de las democracias, contradice la forma democrática de gobierno. Bajo el predominio del poder Ejecutivo se vuelve fundamental el control a este último por parte de la sociedad.

Rosanvallon sostiene que la democracia de ejercicio que él propone es más potente que la idea de calidad democrática introducida por las ciencias políticas. Ésta última pone énfasis en la gestión, pero no en la "redefinición global de la noción misma de democracia” $(2017,159)$.

La democracia de ejercicio debe fundarse en tres principios: la legibilidad ("más amplia y más activa que la transparencia") la responsabilidad y la reactividad (responsiveness en inglés). Con ellos se trata de configurar una democracia de apropiación, en la que los ciudadanos puedan ejercer de manera más directa funciones democráticas, hasta ahora monopolizadas por el poder parlamentario.

El poder, sostiene Rosanvallon, más que una cosa es una relación. Son las características de esa relación "las que definen la diferencia entre una situación de dominación y una simple distinción funcional” $(2017,159)$.

La propuesta del sociólogo francés se sintetiza en la "construcción de una democracia de confianza y de una democracia de apropiación" en la época presidencial gobernante. Estos principios no son aplicables solo al Poder Ejecutivo, sino al "conjunto de instituciones no elegidas que tiene una función reguladora" $(2017,160)$. Con ella se apunta a dar un salto, de la voz del pueblo al ojo del pueblo que consiste en pasar del ciudadano-elector al ciudadano controlador. Esta figura tiene una larga historia, explica Rosanvallon. Viene de la Revolución Francesa cuando los "Amigos de la Libertad" temieron que los ministros se apoderaran de sus destinos.

La vigilancia del pueblo "era comprendida como necesaria para dar vida al ideal de un gobierno guiado por el cuidado del interés general" (2017, 160-161). 


\section{La calidad de la democracia}

El debate actual se centra en la calidad de la democracia, ya no entre democracia formal y gobiernos de facto. Dicha calidad se expresa en la capacidad de nuestras democracias de "entregar calidad (en servicios públicos, en la distribución de riqueza, en cohesión social, entre otros), a todos sus ciudadanos" (Informe, 2014, 32) aspecto que en la teoría clásica de la democracia no se lo consideraba.

La preocupación ahora se centra en cómo pasar de una democracia electoral a una democracia de ciudadanos y de instituciones. Ya no se escinde la política de la economía, cuando se vincula democracia con desarrollo económico, menor desigualdad y pobreza, mayor equidad de género. En lugar de tomar partido bien sea por un estado interventor o por un estado mínimo, se busca una relación más estratégica entre estado y mercado, así como, entre estado y sociedad.

En esa línea de reflexión, sostiene el Informe, que para que las instituciones sean legítimas y eficaces hace falta una buena política. Ésta, a su vez, requiere de liderazgos democráticos. Si se juntan instituciones de calidad, buena política y liderazgos democráticos, es posible llegar a consensos básicos "que sirvan de base para la adopción de una visión estratégica de país" $(2014,25)$ que se concrete en políticas de Estado, capaces no solo "de mejorar la democracia y el desarrollo, sino fundamentalmente la calidad de vida de los ciudadanos" $(2014,25)$.

Los motores que impulsan la calidad democrática son, a juicio de los autores del Informe, la competencia política y la participación ciudadana. Pero la una y la otra, requieren de conocimiento experto. La idea de que los ciudadanos, aun los más instruidos, informados y políticamente comprometidos, siempre conocen sus necesidades y deseos, no se ajusta a la realidad. Requieren, aun sin saberlo, de "conocimientos especializados para identificar y evaluar correctamente dichas necesidades y aspiraciones" $(2014,53)$.

La capacidad de respuesta del gobierno, sin duda, está ligada a este déficit cognitivo. Los líderes electos no conocen ni toman en cuenta las percepciones y posiciones de los ciudadanos, lo cual impide que puedan responder a ellas. No faltan quienes se valen de su poder para "maximizar su propia autonomía e influencia sobre las percepciones y opiniones ciudadanas con respecto a temas de mayor importancia" $(2014,54)$.

Los autores del Informe encuentran conexión entre los procedimientos, y la implementación eficaz de los dos valores democráticos más relevantes, como son, la libertad y la igualdad. Un funcionamiento efectivo de la democracia requiere de capacidad administrativa. Ello implica la existencia de una burocracia profesional, no atada a consignas políticas o partidistas, capaz de asegurar el cumplimiento de las leyes y de garantizar procesos transparentes en los que pueda participar la sociedad civil. Coinciden con Rosanvallon en la alteración que han sufrido las funciones del estado con el predominio del poder Ejecutivo. Éste se apoya en sus equipos económicos, integrados por expertos no elegidos por el pueblo, pero dotados de gran influencia en las decisiones que toman los gobernantes. Ellos marcan las pautas de la acción gubernamental, mientras las potestades de los representantes electos para cambiar las preferencias, son escasas.

La búsqueda de calidad de la democracia no debe confundirse con formas de democracia "iliberal". Ello plantea un debate acerca de qué entender por democracia. Si solo nos atenemos a la gestión de los gobiernos electos podemos calificar de democráticos a líderes que han ganado las elecciones sin necesariamente sujetarse a sus normas y principios. Se trata, afirman los autores del Informe, de una "integración negativa" $(2014,91)$. Esto quiere decir que tras de la fachada democrática se implantan regímenes que hacen uso de una retórica revolucionaria con la que encubren una práctica conservadora. Ello se traduce en la existencia de dos equipos: uno económico y otro de política social. Mientras el primero ejerce políticas ortodoxas (más o menos neoliberales), el segundo, apunta a otra dirección.

\section{La perspectiva política situacional}

En Carta póstuma al Presidente chileno Salvador Allende, su ex Ministro, Carlos Matus le confiesa: "Con usted aprendí de política y recibí lecciones inolvidables de valor y lealtad a la palabra empeñada" (Adiós Señor Presidente, 1994). Las reflexiones que Matus le transmite a Allende, son posteriores al golpe militar de 1973 que acabó con la vida del ilustre mandatario chileno.

"Usted ya no puede beneficiarse de mis reflexiones ni del dramático cambio que ha sufrido el mundo y las ideologías" (1994, Carta, s/p).

Pero quizá a otros puedan servirles estas reflexiones si tienen "la oportunidad de servir a sus pueblos con eficacia y revivir la llama perdida del fervor popular" (cursivas mías) (1994, Carta s/p).

Matus traza su perfil autobiográfico:

"Desde muy joven y a lo largo de muchos años de servicio público pude reflexionar desde variadas y encontradas posiciones sobre el arte y las ciencias del gobierno. Fui estudiante universitario, fui asesor, fui su Ministro, fui profesor e investigador, trabajé como técnico y tuve altas responsabilidades políticas, actué como defensor de su gobierno y también como opositor a la dictadura, y recorrí, en desorden y en diversas geografías, varias veces en mi vida ese ciclo de aprendizaje entre técnica, academia y política práctica ( cursivas mías)antes de 
poner por escrito estas reflexiones" (...) Dos años en los campos de concentración de la dictadura me ayudaron a comprender la miseria, la ingratitud y la nobleza humana, así como la transitoriedad del poder" (1994, Carta, $\mathrm{s} / \mathrm{p}$ ).

Luego Matus resume las lecciones de la experiencia del gobierno de Allende (1970-1973):

El dirigente político al servicio de las mayorías más pobres se forma y templa en la lucha. Ello le impide prepararse para gobernar. "Usted supo que gobernar es una tarea dura, mucho más compleja y de naturaleza distinta a la de ganar elecciones." (1994, Carta s/p).

El dogmatismo de un sector de los partidarios de Allende, "los incapacitó para adoptar una estrategia y una línea táctica que encauzara coherentemente el gobierno" (1994, Carta, s/p). Pero esos mismos partidarios, cuando "se derrumbó el mundo que les sirvió de guía" (1994, Carta s/p) se replegaron hacia el lado opuesto de los ideales que asumieron con aparente lealtad.

Hoy, afirma Matus, vivimos dos desventuras: la crisis de las ideologías y la pobreza de los métodos de gobierno. Frente a ellas Matus optó por encarar la segunda. La primera para él es harto compleja. "Estoy consciente que he dejado de lado lo sustantivo, y me he volcado sobre lo adjetivo." (1994, Carta s/p). Pero lo adjetivo no es menos importante: "por fallar en lo adjetivo muchas buenas y malas intenciones se van al infierno de la ineficacia y el caos. América Latina ofrece muchos ejemplos de fallas gigantescas en las herramientas de gobierno cometidas bajo el alero de proyectos políticos progresistas, mientras una corte de halagadores, sin el mínimo rigor crítico, perpetúan y viven de esas experiencias frustrantes" (1994, Carta s/p).

Además, las dos calamidades no son independientes. "Las víctimas del ideologismo extremo desprecian las ciencias y las herramientas de gobierno" (1994, Carta s/p). Ocupándose, entonces, de la segunda contribuye a encontrar la manera de rescatar el valor de las ideologías.

Desconozco si Rosanvallon está enterado de la obra de Matus recogida en sus múltiples estudios, cursos y libros. Pero pienso que hay coincidencias conceptuales que vale la pena resaltar.

Rosanvallon enfatiza en la desconexión y discontinuidad entre elecciones y gobierno. Señala que la relación entre gobernantes y gobernados ha desplazado en importancia a las relaciones de representación. Más que el imperio de la ley en la práctica cuentan las decisiones emanadas de la función Ejecutiva que en realidad se ha convertido en el primer poder del
Estado, desplazando al poder Legislativo, a cuyos representantes no es posible exigirles que se responsabilicen por sus actos u omisiones. La responsabilidad individual de los representantes tiende a diluirse en la responsabilidad de todos. La cabeza de la Función Ejecutiva no puede evadir su responsabilidad por las decisiones y actos que realiza. Ello lo convierte en el destinatario directo de los reclamos y demandas de los distintos grupos sociales.

Fórmula el concepto de situaciones sociales que pesan más, según él, que las condiciones sociales. Los individuos no permanecen atados a una sola identidad. Más que a ella responden a los acontecimientos vividos, a la dinamia de la existencia individual. Entiende al pueblo como una sucesión de historias singulares, una suma de situaciones específicas. Esta podría ser una de las causas de la crisis de representación de los partidos políticos.

Esta heterogeneidad se expresa también en las elecciones. Los electores son individuos de carne y hueso, no son una masa. Su voto tiene la mar de motivaciones. Por eso no se puede hablar de "voluntad general" ni de pueblo en sentido abstracto.

La segunda revolución democrática que propone Rosanvallon tiene un gran valor sustantivo. Lo que él no explica es cómo ese proyecto sustantivo puede hacerse realidad. Aquí le faltan los ingredientes operacionales, o sea, deja de lado lo adjetivo que es el gran aporte de Matus. Tampoco muestra la interacción entre el momento electoral y el momento del ejercicio del poder. Matus, en cambio, valora las incidencias de la contienda electoral en la conformación del gobierno. También, las consecuencias que un mal o buen gobierno pueden tener en los eventos electorales siguientes. Solo de pasada Rosanvallon se refiere a la acción gubernamental, es decir, a la "gestión cotidiana de los asuntos públicos, la instancia de la toma de decisiones y de mando" (2017, 157). Minimiza este punto y se concentra en grandes ideas, pero sin conexión con la práctica.

En cuanto a los autores del Informe para IDEA Internacional, tampoco sé si están enterados de los aportes teóricos y metodológicos de Matus. Cabe, sin embargo, resaltar que la comparación que hacen de las democracias de la región se basa en la calidad de la democracia, y ya no solo en las elecciones que han tenido lugar en los últimos cuarenta años. Esto, sin duda, es un avance.

Así encuentran democracias de baja, mediana y alta calidad, a juzgar por los resultados alcanzados. Ya hablan de la democracia como forma de gobierno y no de manera abstracta como régimen. Se basan en un análisis empírico, a partir de dimensiones, subdimensiones 
y preguntas orientadoras clave. Combinan el análisis de datos cuantitativos con el análisis de datos cualitativos. Arman un marco teórico que no formule ningún juicio de valor. Tratan del entramado institucional y no de los actores que se disputan el poder. Es una mirada neutra, no comprometida con ninguna posición ideológica o política.

Desde mi perspectiva, es relevante advertir que el Informe es una investigación con base empírica, a diferencia del análisis de Rosanvallon que es un estudio teórico. Es una investigación realizada por un equipo internacional de científicos sociales, expertos e investigadores que, durante más de dos años, en base a una metodología de análisis de la calidad de la democracia, intenta medir el estado de las democracias en la región. La explicación que formulan es, por tanto, una explicación no suscrita por ningún actor en particular, ni por un gobierno, o movimiento social. Es una explicación desde afuera de las situaciones vividas en cada país, a lo largo de las últimas décadas. Muy similar a esos trabajos académicos que elaboran las universidades o los institutos de investigación para múltiples destinatarios. Se emiten, sin embargo, apreciaciones subjetivas como esta: "En general lo que está primando en la política latinoamericana es la moderación, el pragmatismo y una tendencia hacia el centro (ya sea desde la izquierda o desde la derecha)" $(2014,14)$. Esta afirmación queda relativizada en el mismo párrafo del Informe, cuando se hacen distinciones en América del Sur, en América Central, y se constata que la tendencia hacia el centro no es lo que prevalece.

En el Ecuador, por ejemplo, en el 2007 se planteaban alternativas ideológicamente polares. La situación del Ecuador desde el punto de vista histórico se aproximaba más a Venezuela que a Chile. Los sectores populares querían remedios a sus problemas que no demoraran tanto. La irrupción de un líder carismático que se mostraba dispuesto a actuar sin apego a las instituciones y normas formales, atrajo la adhesión de sectores sociales marginados que habían soportado estragos sociales y económicos con el feriado bancario y la dolarización.

\section{La perspectiva del hombre/mujer de acción}

Por las ideas que Matus transmite a su ex presidente, salta a la vista que se trata de un hombre de acción que tomó partido por el proyecto político que lideró Salvador Allende. Y Salvador Allende fue un líder de talla histórica que se jugó por un proyecto que implicaba afectar grandes y poderosos intereses. A Matus no le era ni fue indiferente lo que aconteció con el derrocamiento de su gobierno por los militares. Curiosamente por ahí empieza una revalorización de la democracia por parte de intelectuales de izquierda, comprometidos con la primera revolución socialista que apostaba a las urnas. Frente a la arremetida de Augusto Pinochet tomaron conciencia de que las libertades y derechos humanos no eran algo secundario frente a la transformación estructural que aspiraban a lograr con el gobierno de la Unidad Popular. La tercera ola de democratización en América Latina está vinculada al arrasamiento de la democracia sufrida por el pueblo chileno. La transformación estructural anhelada no podía hacerse con sacrificio de la democracia. Esa fue la gran lección que dejó la experiencia chilena.

Matus también fue víctima de esa acción devastadora cometida por un régimen represivo que sepultó la democracia en nombre de la salvación del capitalismo, amenazado por el gobierno popular de Salvador Allende. En su reclusión en las islas Dawson y Ritoque, Matus pasó dos años reflexionando sobre su vida y experiencia en la CEPAL y en el gobierno de Allende. Fruto de esas reflexiones son sus libros sobre Planificación y Gobierno, sobre Liderazgo, los Tres Cinturones de Gobierno y finalmente su Teoría de Gobierno.

En ésta fecha (1998) Matus formula planteamientos teóricos, políticos y metodológicos de gran profundidad, orientados siempre a la práctica de la acción. Así descubrió que en torno a las elecciones se libran luchas por el liderazgo, por espacios de poder, por mezquinos intereses de grupo o de partido. A este campo lo denominó micropolítica, para diferenciarlo de la política con mayúsculas que gira alrededor de los grandes principios de la democracia y del interés general.

Su apuesta era colocarse en los zapatos de los políticos y de los gobernantes para entenderlos y equiparlos con herramientas y técnicas de gobierno, capaces de elevar su desempeño en el ejercicio de las funciones para las que fueron electos.

Era consciente de la propensión de los políticos al inmediatismo y a la improvisación, pero sabía que, si no se los encaminaba hacia otras formas y estilos de hacer política, difícilmente, mejoraría la calidad del gobierno, y, por ende, de la democracia.

Poniéndose en el lugar de los gobernantes, dibujó el triángulo en el que se desenvuelve todo gobierno. En el vértice se ubica el proyecto con el que se comprometió en la campaña electoral; en la base ubica la capacidad de gobierno con la que ese funcionario llega al poder; $\mathrm{y}$ en tercer lugar, delinea la gobernabilidad del sistema en su conjunto. Dependiendo del alcance del proyecto, la capacidad de gobierno debe ser más alta o más baja. Un proyecto muy ambicioso, como lo fue el de la Unidad Popular en Chile, requería de una alta capacidad de gobierno. En este mismo caso la gobernabilidad del sistema fue muy baja, dado el poder de las fuerzas internas y externas que se opusieron al mismo. 
"El resultado de las elecciones parlamentarias del 4 de marzo de 1973 ha dado al traste con el "golpe blando". La Unidad Popular ha tenido un éxito más allá de los esperado en las urnas. La conjura tiene que decir adiós a su plan de destituir al Presidente de la República. Declara cancelado el camino legal. Opta por la sedición armada" (Volodia Teitelboim, Neruda, 1996, 481).

Este triángulo, por tanto, se compone de variables interrelacionadas. El gobernante, está limitado por la gobernabilidad del sistema, así como por el alcance de su proyecto y por la capacidad de gobierno. Ésta no se refiere exclusivamente a la capacidad personal del líder, sino a la capacidad institucional, a la calidad de la burocracia, de sus asesores, a la experiencia acumulada.

Es aquí en la capacidad de gobierno donde Matus centra su atención. Él apuesta a la capacidad de gobierno como eje de un cambio cualitativo del funcionamiento de la democracia. Muchas veces la baja capacidad de gobierno lleva a los gobernantes a desistir de sus programas y a caer en una acción defensiva y reactiva. En otras ocasiones, los líderes cesaristas cifran su acción en su voluntad y en una suerte de ampliación desmedida de su gobernabilidad, mediante la concentración de funciones y la represión a sus adversarios. En este caso, la política es entendida como confrontación permanente, lo cual atenta contra la cohesión social y el encuentro de equilibrios políticos que le den sostenibilidad a la democracia.

Pero por la baja capacidad de gobierno cometen errores de gran magnitud y dejan escapar la oportunidad histórica de construir una democracia de ejercicio. Siguen apostando a la democracia electoral, a través de plebiscitos y de la reelección.

En ese sentido son más conservadores que progresistas.

Para elevar la capacidad de gobierno los líderes precisan de un estado mayor integrado por personal altamente calificado que le brinde soporte cognitivo. Esto no es lo mismo que el soporte afectivo que el líder requiere para reposar de las presiones y tensiones que implica el ejercicio del gobierno. Ello es tanto más necesario si los líderes optan por encaminar a su gobierno por la línea del enfrentamiento de los problemas sociales. En cambio, si se dejan arrastrar por la línea de la acumulación del poder, no necesitarán de equipos altamente calificados, pues la competencia por la acumulación de poder es más simple que la competencia por "gobernar con eficiencia, eficacia y aceptabilidad".

Ello, sin embargo, es relativo. Las reglas del juego político electoral también exigen habilidades especiales, lo que Matus entiende como capacidad política.
La competencia entre la micropolítica y la política se desarrolla interactivamente. No es posible tampoco menospreciar la micropolítica, pues es en ese espacio que se libran las luchas por el poder. La política con mayúsculas no puede prosperar sin capital político, y éste es provisto por los juegos que tienen lugar en la micropolítica.

En este punto Matus agrega que el divorcio entre lo que los ciudadanos demandan de la política y lo que la política y los políticos realizan, es producto también del abismo entre la política y las ciencias sociales, entre la práctica y la teoría $(1998,2)$. Ello también incide en la baja capacidad de gobierno. Los políticos no tienen un asesoramiento adecuado. Las universidades proveen de profesionales especializados en fracciones del saber. En las universidades prevalece el conocimiento departamentalizado, lo que no permite ver y analizar los problemas que atraviesan horizontalmente la práctica social. De ahí que los políticos solo trabajan con "malestares imprecisos y con soluciones preconcebidas" $(1998,2)$.

Eso con relación a los políticos. Pero no hay cómo suponer que los ciudadanos saben lo que en realidad necesitan. Los autores del Informe citado aciertan cuando afirman que la idea de que los ciudadanos, incluso instruidos, preparados y políticamente comprometidos, siempre conocen sus necesidades y deseos, es un supuesto débil. La adhesión que recibieron Hitler y Mussolini en Alemania e Italia, respectivamente lo demuestra. Igual que los líderes populistas en América Latina.

La política también está atravesada por la ideología. El caso de Chile es elocuente. Los planteamientos de Rosanvallon apuntan a una segunda revolución democrática que supone poner en debate la democracia liberal y que aboga por una redefinición global de la noción misma de democracia. La afirmación de que el poder no es una cosa sino un relación y que las características de esta relación definen la diferencia entre una situación de dominación y una simple distinción funcional, no permite evadir la implicación ideológica de esta redefinición.

En el Post Scriptum del Informe, Juan Rial se refiere a la "integración negativa" de dirigentes o militantes de izquierda que apelaron a formas de populismo de carácter movilizador que "cedió el paso a la implementación de prácticas de las viejas oligarquías conservadoras." (2014, 91). Y agrega "hoy el populismo supone no mucho más que un cambio de discurso, sumado a prácticas de "clientelismo horizontal" $(2014,91)$.

Desde otro ángulo, Matus sostiene que con baja capacidad de gobierno ningún modelo puede funcionar bien, sea el que pretende acentuar o mantener la regulación fuerte del estado o el que intenta implan- 
tar el modelo neoliberal. Al respecto, a su criterio, esta discusión se ha visto teñida de extremismo. Si bien no cabe desconocer el contenido ideológico de este debate, tampoco cabe esperar que uno u otro modelo tengan éxito sin la capacidad de gobierno necesaria (El líder sin Estado Mayor 1997, 23). Lo que sigue es una síntesis de esta propuesta formulada por Matus en Diez Tesis sobre las Prácticas de Gobierno (separata, s/f).

\section{Perspectiva política de corto plazo}

Siguiendo a Carlos Matus, en sus Diez Tesis sobre las Prácticas de Gobierno, el triangulo de gobierno se vuelve más problemático manejarlo en el corto plazo. Los gobiernos están limitados en el tiempo. Su duración es corta. En ese lapso deben alcanzar los objetivos anunciados en la campaña electoral. La tentación del inmediatismo es muy fuerte, si respetan la legalidad; la otra tentación reñida con la legalidad es alargar el período de gobierno con miras a perpetuarse en el poder. Ello no sólo responde a afanes hegemónicos, sino a la dificultad de hacer realidad su proyecto.

Hay un déficit de previsión de los gobiernos. En el corto plazo tal déficit es irrecuperable. Los gobiernos no pueden darse el lujo de dejar para el fin de su mandato las consecuencias de cada decisión. Cuando lo inmediato ocupa la atención de los gobernantes, las $u r$ gencias prevalecen sobre las importancias. Así el gobierno se diluye en acciones escasamente articuladas. Son gobiernos reactivos que suelen verse sorprendidos por los hechos. En tal caso, son los hechos los que marcan la ruta. No hay capacidad política de conducción. Esta situación se agrava por la carencia de equipos de gobierno debidamente formados, lo cual afecta la capacidad de gobierno. Tales equipos son inestables, con lo que se merma la continuidad de la acción del gobierno. Son frecuentes las contradicciones al interior del propio gobierno. Tal inestabilidad también responde a los cambios en las relaciones entre el gobierno y la oposición. A las vicisitudes de la economía. A la mayor o menor desafección social. No se ve más allá de la coyuntura. No hay un planteamiento integral de gobierno. Es frecuente la desconexión de los temas.

Bajo el imperio de la improvisación, el margen de error es muy alto. Los objetivos de mediano y largo plazo ocupan los últimos lugares de la agenda, mientras el descontento de la población crece frente a la acumulación de problemas que más le afectan y sobre los cuales los gobiernos no toman decisiones ni oportunas ni eficaces. Hay presidentes para quienes su período de gobierno se vuelve demasiado extenso, pese a su brevedad. Su futuro inmediato y el de su partido se ven truncados por la pobreza de resultados alcanzados en su gestión. Acosados por las presiones electorales, los tomadores de decisiones ven aumentada su vulnerabilidad. No se ve más allá de la coyuntura. Las prioridades de su gestión están determinadas por ese cálculo inmediato y no por la evaluación posterior.
Esta falta de vinculación entre los tres ejes del gobierno produce un círculo vicioso entre el presidente saliente y el entrante. Eufórico, el presidente entrante capitaliza electoralmente el descontento de los ciudadanos respecto del gobierno que concluye su mandato, pero, dado el imperio del corto plazo y la reedición de similares circunstancias, está condenado a repetir los errores de su antecesor. Nada garantiza que el presidente entrante sea mejor que el saliente. El éxito de un gobierno, más que de su orientación ideológica -que, por cierto, importa- depende de la capacidad que demuestre para resolver los problemas que le afectan a la población.

Gobernar implica una selección de problemas. "Un proyecto de gobierno es una propuesta de intercambio de problemas" (Matus, 1997, 56-57). En ella pesa la ideología. En una coyuntura de crisis la estabilidad económica plantea una disyuntiva entre inflación y cesantía. Optar por reducir la inflación implica aumentar el desempleo. Optar por reducir el desempleo trae consigo un aumento de la inflación. El gobernante debe, por tanto, hacer un balance de los costos y beneficios de cada opción antes de tomar una decisión. Optar por lo uno o lo otro, supone un intercambio de problemas. Optar por la austeridad implica un ajuste de cinturones que usualmente genera reacciones sociales y una merma de la popularidad del gobierno. Optar por el gasto público, permite una redistribución de recursos, pero también puede ocasionar una disminución del ahorro y de la inversión productiva.

Un gobernante tiene que sopesar los costos y beneficios de las medidas que adopta en función de los objetivos de su gobierno. La gobernabilidad de un gobierno puede verse afectada según el intercambio de problemas definidos. En el caso ecuatoriano, en la vuelta a la democracia, los gobernantes optaron por "sacrificar los principios a la realidad" (Moncayo, La planificación estatal en el interjuego entre desarrollo y democracia, 2017, 260 y ss.). Los objetivos de un gobierno neoliberal son distintos de los de un gobierno de tinte socialista, pero ni el uno ni el otro, pueden hacer abstracción de la realidad. Las estrategias de gobernabilidad también varían en ambos casos.

\section{Las estrategias de gobernabilidad}

La gobernabilidad señala Matus es relativa a cada actor. Un sistema social no es igualmente gobernable o ingobernable para los distintos actores. Cada actor controla "una porción distinta de variables del sistema" . Ello se ve afectado también por el contenido propositivo del proyecto de gobierno. El sistema es más gobernable para un gobierno moderado o conservador. Es, en cambio, menos gobernable para objetivos ambiciosos y redistributivos. También cuenta, por cierto, la capacidad de gobierno de cada actor. "La gobernabilidad expresa la capacidad de resistencia que ofrece el sistema 
político social a un proyecto de gobierno y al actor de ese proyecto" (Matus, 1997, 13). Si los objetivos son menores, no hace falta mayor capacidad de gobierno, en cuyo caso, la estrategia es no hacer olas. Por el contrario, si un gobierno se propone una transformación social, la estrategia no puede apoyarse solamente en el poder alcanzado, sino en la relación de fuerzas en el campo político.

Ello se aclara si se parte de la configuración social de las fuerzas en juego. Simplificando el ejemplo, los partidos que defienden el statu quo, no pueden colocarse muy cerca de las clases dominantes, pues ello exacerbará la resistencia y oposición de las clases subordinadas. De la misma manera, los partidos que cuestionan el orden establecido no pueden excederse en las concesiones a favor de las clases subordinadas y, en perjuicio de las dominantes.

Las estrategias de gobernabilidad no deben soslayar los equilibrios de poder entre las clases sociales polares de la sociedad. Las estrategias antihegemónicas (esto es, las que intentan imponer una ideología contraria a la ideología dominante y una estructura de poder excluyente) alteran ese balance y apuestan al autoritarismo, con lo cual no garantizan la sostenibilidad del proyecto alternativo. Tales estrategias tienen un sesgo antidemocrático no obstante practicarse bajo formas democráticas.

En épocas de crisis económica, se producen vuelcos en la acción de los gobiernos. Hasta los gobiernos progresistas se ven obligados a moderar el alcance de sus metas y acciones. En estos casos, se privilegian las estrategias de gobernabilidad cifradas en la corrección de los desequilibrios macroeconómicos. Hacerlo tiene un costo social que puede desembocar en desequilibrios políticos. También hay, en sentido contrario, estrategias que privilegian los halagos políticos, sin medir su costo en términos económicos. No hay un balance entre los efectos económicos y políticos en las decisiones de política pública, lo cual genera amenazas de desestabilización del orden democrático. El caso ecuatoriano ilustra con claridad este desbalance. (Moncayo, 2017, 262-265).

\section{Conocimiento y acción}

A lo largo de la historia de Occidente se ha planteado como opción para obviar los problemas antes expuestos, el gobierno de los sabios. Ello entraña una postura elitista y, por tanto, antidemocrática. Apelar a la sabiduría de los expertos, se argumenta, permite superar la "ignorancia congénita de las masas". Una cosa, dicen, es garantizar que las decisiones se ajusten a la voluntad de las mayorías, otra distinta, sostienen, es garantizar que esas decisiones sean las más inteligentes.

El valor que se concede al conocimiento experto, según este enfoque, parte del supuesto de que "cualquier plantel de técnicos reflexivos" coinciden en las soluciones, pero lo que falla es "la capacidad de decisión". "Ni el gobierno ni la oposición actúan hoy por criterios fundados en el conocimiento técnico, sino por criterios que modulan y manipulan ese conocimiento en función de intereses partidistas" (José María Ruiz Soroa, El País, 19 de sep. 2012).

Los técnicos, por su alto grado de especialización, ven partes de la realidad social. Los políticos, por el contrario, deben mirar el conjunto. El asesoramiento técnico no abarca la totalidad del campo en el que actúa el político. Éste se ve obligado a decidir sobre problemas globales sin contar con el asesoramiento técnico requerido. Los técnicos subvaloran lo político, tienden a tratar la economía separada de la política. Por su, parte los políticos carecen de conocimientos económicos y se apoyan en su intuición y experiencia. Los equipos de gobierno, por tanto, carecen de un método común de trabajo que integre lo político y lo técnico. No existe la capacidad tecnopolítica para adentrarse en el fondo de las situaciones en las que se desenvuelve un gobierno. Ello afecta la calidad de las decisiones. De esa manera los grandes problemas nacionales se acumulan e intensifican, al ser enfrentados sin el debido procesamiento técnico y político.

Las universidades y los organismos de cooperación internacional no han dado a este tema la importancia que tiene. Tampoco los partidos políticos, arrastrados por el electoralismo. No hay escuelas de gobierno ni tampoco un conocimiento de las nuevas técnicas y ciencias de gobierno. Las teorías y conceptos que prevalecen en los círculos académicos ya no responden a las nuevas condiciones del mundo actual. La práctica termina siendo la única escuela en la que se forman los presidentes. En palabras de Francisco Martín Moreno (El País, 4 ago. 2016) "los aciertos y errores, las consecuencias y los beneficios de tan difícil e inoportuno aprendizaje habrán de padecerlos o disfrutarlos las naciones en su conjunto"

"Un presidente no está preparado para tratar con banqueros extranjeros, con los gobernantes de las grandes potencias, tampoco con el Congreso, con la prensa, con el narcotráfico, la trata de blancas o negras, la elusión tributaria por medio de paraísos fiscales o con los problemas de sanidad o la explotación laboral de menores". Todos, dice Martín:" banqueros, funcionarios, intelectuales, columnistas, políticos, empresarios, caricaturistas, curas y periodistas se presentan con su mejor traje. El baile de las máscaras no tiene fin. Al jefe de Estado le corresponde encontrar la verdad oculta en cada planteamiento, el interés inconfesable en cada sugerencia, el verdadero motivo en cada propósito".

No se ven los problemas de la práctica; la formación que proveen las universidades no le dan al profesional capacidad para resolver dichos problemas. ¿Cómo se analizan esos problemas? ¿Con modelos matemáticos? Dado que estos problemas tienen "variables imprecisas, difusas, nebulosas" el dirigente 
formado en las universidades se vale de su intuición o de su olfato (Matus, 1998, 4).

La baja capacidad de gobierno se expresa en la incapacidad para procesar problemas, pero no los problemas con causas y efectos precisos, sino esos otros problemas de los que sabemos muy poco sobre sus causas y efectos. Y la mayor parte de los problemas de la vida real son de este tipo. Esta es la diferencia entre un problema social y un problema científico. "La causalidad científica no es correspondiente con la causalidad del proceso social" (Matus, 1998, 2-3). "La interrogante científica trata de comprender una parcela de un fenómeno, y pregunta por la relación pura, y libre de otros efectos" (1998, 2-3).

\section{La democracia del buen gobierno}

Pierre Rosanvallon dice, "la democracia organiza el tiempo electoral pero no organiza el tiempo gubernamental". Y utiliza una buena metáfora: "las elecciones dan a un grupo permiso de gobernar, pero no un "código de gobierno". El gobierno ya no es sólo el sistema de representación, sino la "organización del vínculo entre los ciudadanos y los gobernantes" $(2017,158)$. Pero ello exige analizar y comprender la crisis de liderazgo. El problema del "mal gobierno" está en las cabezas dirigentes, cuyo capital intelectual ha sido sobrepasado por la complejidad de los problemas de la realidad. No hay conciencia sobre las incapacidades de conducción. Lo más atrasado en América Latina, dice Carlos Matus, es la oficina del dirigente. Esto expresa una baja experticia política integrada por la experiencia y el capital intelectual. Ambos componentes son indispensables: cuando se cuenta con el uno y no con el otro, la experticia "vale cero" (Matus, Diez Tesis).

Si a ello se añade" la gran crisis ideológica y el grave deterioro de la ética social", la democracia sufre los embates de la corrupción, del tecnocratismo y del populismo. El primero es producto del relajamiento del control democrático; el segundo, emerge como salida a la confusión ideológica; el tercero, responde a la incapacidad de plasmar en políticas públicas los programas de gobierno y a la apropiación personal del poder.

Matus sostiene que la salida a esta crisis de liderazgo es la planificación estratégica situacional. El político que hoy no sabe de dirección y planificación es gobernado por las circunstancias. "Gobierna quien planifica y planifica quien gobierna", dice Matus (Diez Tesis). La experiencia del llamado socialismo del siglo XXI en el Ecuador, sin embargo, aplicó este principio colocando a la oficina de planificación como caja de resonancia del Ejecutivo y de quien lo presidía.

\section{Sistemas de baja responsabilidad}

Lo que se conoce como prestación y cobranza de cuentas por desempeño no logra un verdadero control de los gobernantes. Los métodos que se utilizan son asistemáticos y muy parciales. En realidad, el Presidente de la República no rinde cuentas al Congreso ni éste pide cuentas al Presidente. Éste, a su vez, tampoco exige cuentas del cumplimiento de sus planes a sus ministros. De esta manera nadie se hace responsable de los errores y aciertos del gobierno.

Como consecuencia, señala Matus, todos los grandes problemas de América Latina se han agravado, al no ser enfrentados con seriedad y eficacia.

Para superar este problema se necesita que las cabezas dirigentes cambien sus patrones de conducta y reciban un entrenamiento en alta dirección. En esta línea los partidos políticos deberían crear centros que impartan este conocimiento.

\section{Conclusiones}

El análisis que antecede ofrece una posible explicación del auge del autoritarismo, bajo el camuflaje de la democracia.

Los problemas del mal gobierno son comunes a todas las ideologías; la crisis ideológica ahonda los riesgos de la manipulación de la democracia; la baja capacidad de gobierno lleva a la emergencia del populismo y/o del tecnocratismo, con los cuales se cuelan distintas variantes de autoritarismo. La corrupción encuentra terreno propicio para expandirse, ante la ausencia de un sistema de control institucional y ciudadano continuo.

La relación entre gobernantes y gobernados no debe circunscribirse al momento electoral. Los programas de gobierno no deben ignorar los obstáculos y restricciones; su cumplimiento en gran medida depende más de la capacidad de gobierno que de la voluntad o del poder. También su cumplimiento debe ser objeto de escrutinio público, a través de mecanismos efectivos y sistemáticos de petición y rendición de cuentas.

La crisis de liderazgo no puede ser resuelta, sin el aprendizaje de las nuevas ciencias y técnicas de gobierno. Las universidades no proveen de este tipo de conocimiento y herramientas. El aprendizaje de gobernar no debe hacerse durante o después, sino antes de acceder al poder, de ahí la importancia de los partidos políticos como centros de formación de los líderes; éstos no pueden limitarse a la participación en la contienda electoral, dado que el ejercicio de poder demanda experticia para implementar los programas de gobierno. Las elecciones deben ser aprovechadas para la educación de la ciudadanía en democracia. Los ciudadanos deben demandar a los candidatos la solución de sus problemas más acuciantes y exigirles compromisos a ser cumplidos en su gestión.

El aprendizaje de los políticos que asumen tareas de gobierno incluye disminuir la departamentalización del saber. Ello hará posible conjugar, por ejemplo, una buena economía con una buena política. No sólo aten- 
der al déficit económico sino al déficit de la democracia. Si no hay recursos económicos que repartir, es posible repartir el poder. La descentralización del poder lo hace posible.

En América Latina, por lo general, se ha impuesto la micropolítica, copando la agenda del político, estilo que se transfiere a las funciones de gobierno, afectando su desempeño. Es esta manera de entender y practicar la política que pesa en la baja calidad de la democracia y genera el menosprecio de la gente hacia el político, la política y la democracia. Sin embargo, la gran política muchas veces demora en ser comprendida y aceptada por la ciudadanía. Involucrarla en la gran política supone un largo proceso. La micropolítica ha desplazado a la política: hay un vaciamiento de la representatividad de los partidos políticos y las organizaciones sociales, debido a la fragmentación y atomización de intereses que han desplazado los objetivos generales por cálculos meramente electorales y de conveniencias circunstanciales. Hace falta rescatar la política, entendida como la actividad orientada hacia el bien público. Ello implica la práctica de la deliberación con el más amplio ejercicio de la libertad de pensamiento y expresión.

Hay consenso sobre los déficits de la democracia. Los matices radican en cómo encararlos y superarlos. La magnitud de los problemas que atañen al mal gobierno y lo que representa forjar un Buen Gobierno, supone, en verdad, una segunda revolución democrática. Ella, por cierto, no puede producirse con métodos primitivos de gobierno ni con liderazgos micropolíticos. Se necesitan líderes competentes no solo para ganar elecciones, y líderes a los más distintos niveles. Líderes históricos capaces de abrir caminos. La capacidad de gobierno no es atinente solo a los altos puestos de la dirección del estado, sino a los distintos niveles de la acción social. Falta en el Informe de IDEA la contextualización histórica en la que se insertan las tendencias de derecha, centro e izquierda. No es posible comparar las democracias de la región haciendo abstracción de su trayectoria histórica.

En las asignaturas pendientes( 2014,14) el Informe destaca los siguientes: el desajuste entre la política y la sociedad; la desadaptación de los partidos políticos respecto de las sociedades mismas; la baja gobernabilidad de los regímenes democráticos; el defectuoso funcionamiento de los poderes del Estado. Los expertos se centran en seis grandes desafíos: debilidad de las instituciones democráticas; el excesivo presidencialismo y el auge de la reelección; altos niveles de corrupción y opacidad; elevados niveles de inseguridad; ataque a la independencia de la justicia y a la libertad de expresión; necesidad de fortalecer la participación y presencia de la mujer. Luego, hacen una revisión de lo que se ha ganado y perdido en distintos campos: económico, político, institucional. A partir de esa constatación, los autores del Informe vislumbran cuatro necesidades: recuperar el consenso sobre el concepto de democracia; necesidad de instaurar elecciones con integridad; necesidad de fortalecer las instituciones; necesidad de incorporar a grupos vulnerables y minorías.

Así queda abierto el debate entre lo adjetivo y lo sustantivo. ¿En qué medida lo adjetivo puede "revivir la llama perdida del fervor popular", frase que utilizó Matus en la Carta póstuma a Salvador Allende? Podría decirse que Matus apuesta a los políticos como sujetos de la transformación de la micropolítica. Apuesta difícil de alcanzar, dadas las prácticas tan arraigadas de la partidocracia.

Ligar las reflexiones aquí expuestas y abrir un debate en torno a ellas, es un imperativo no solo de los partidos políticos sino de los más diversos ámbitos de la sociedad. Las responsabilidades sobre el funcionamiento y resultados de la democracia son compartidos por gobernantes y gobernados. Ello exige pasar de lo adjetivo a lo sustantivo. Los métodos de gobierno no pueden cambiar sin un cambio cultural. Se impone, consiguientemente, ocuparse también de la crisis ideológica, en un mundo que ya no es igual al del siglo pasado.

La relación del líder con la historia es de doble vía. Tolstoi la examina al relatar el curso general de los acontecimientos en La Guerra y la Paz (Tolstoi La Guerra y la Paz, 2004, 903-906). Esta distancia, entre la visión del líder y la que impera en su época, marca los giros de la historia. El cambio de época demanda una democracia en ejercicio.

\section{REFERENCIAS}

[1] - Cheresky, Isidoro (compilador) Elecciones presidenciales y giro político en América latina, 2007, Manantial, Buenos Aires, Argentina

[2] - Matus, Carlos, Adiós, Señor Presidente, 1994, Fondo Editorial ALTADIR, Caracas, Venezuela.

[3] El líder sin Estado Mayor, 1997, Fondo Editorial ALTADIR, Bolivia.

[4] _ Teoría de la Producción Social y Juego Social, 1998, Fundación ALTADIR, Isla Negra, Chile.
[5]_Los 3 cinturones del gobierno, 1997, Fundación ALTADIR, Venezuela

[6] _ Diez tesis sobre las prácticas de gobierno, s/f.

[7] - Moncayo, Patricio La planificación estatal en el interjuego entre desarrollo y democracia, 2017, Flacso, Quito, Ecuador.

[8] - Rosanvallon, Pierre La democracia del siglo XX, revista Nueva Sociedad, No 269, mayo-junio de 2017.
[9] - Teitelboim, Neruda, 1996, Editorial Sudamericana, Chile.

[10] Tolstoi, Lev La Guerra y la Paz, 2004, Penguin Clásicos, Colombia.

[11] - Varios autores, La calidad de la democracia en América Latina, 2014 Informe para IDEA Internacional, Costa Rica. 